\title{
Abnormal Oxidant Sensitivity and Beta-Chain Structure of Spectrin in Hereditary Spherocytosis Associated with Defective Spectrin-Protein 4.1 Binding
}

Pamela S. Becker, Jon S. Morrow, ${ }^{*}$ and Samuel E. Lux

Division of Hematology-Oncology, The Children's Hospital and Dana-Farber Cancer Institute, Harvard Medical School, and Program on Cell and Developmental Biology, Division of Medical Sciences, Harvard University, Boston, Massachusetts 02115; and ${ }^{*}$ Department of Pathology, Yale University School of Medicine, New Haven, Connecticut 06510

\begin{abstract}
Hereditary spherocytosis (HS) is an inherited disorder of erythrocyte shape associated with spectrin deficiency and hemolytic anemia. In a subset of patients with the autosomal dominant form of HS, spectrin displays a reduced capacity to bind protein 4.1 and, therefore, actin; both functions that are critical to the membrane skeleton. A specific structural defect has not been identified in the spectrin from these patients. Chymotryptic digestion of the isolated spectrin chains shows impaired cleavage of the distal peptide of the beta subunit, the beta IV domain. In previous work, we have shown that mild oxidation markedly diminishes the binding capacity of normal spectrin for protein 4.1. Here we observe that chemical reduction of freshly isolated, untreated HS spectrin dramatically improves its function. Thus, a primary structural defect in the beta subunit of spectrin in this subtype of HS may lead to oxidant sensitivity, and secondarily, to a functional defect in the binding of spectrin to protein 4.1 and actin.
\end{abstract}

\section{Introduction}

Hereditary spherocytosis (HS) ${ }^{1}$ is a hemolytic anemia characterized by spheroidal cell shape and increased erythrocyte osmotic fragility. Numerous reports have described altered physiological properties of erythrocytes from patients with HS (for review, see reference 1), but the primary molecular defect responsible for this disorder has not been defined. Recent studies suggest a problem with the erythrocyte membrane skeleton. The red cell membrane skeleton is the network of proteins underlying the lipid bilayer that maintains cell shape and membrane stability (2). The major protein, spectrin, is a heterodimer comprised of two nonidentical linear subunits designated alpha and beta. Each

Portions of this article were presented at the American Society of Hematology meeting, San Francisco, CA, December 1983. Part of the work appeared in abstract form (1983. Blood. 62:43a).

Address reprint requests to Dr. Samuel E. Lux, Division of Hematology-Oncology, Enders 7, The Children's Hospital, 300 Longwood Ave., Boston, MA 02115. 1987.

Received for publication 5 June 1986 and in revised form 10 March

1. Abbreviations used in this paper: buffer A, $10 \mathrm{mM}$ Tris, $150 \mathrm{mM}$ $\mathrm{NaCl}, 0.1 \mathrm{mM}$ EDTA, pH 8; DFP, diisopropylfluorophosphate; DTT, dithiothreitol; HS, hereditary spherocytosis; IAEDANS, 5-(iodoacetamidoethyl)aminonaphthalene-1-sulfonic acid; $\mathrm{mBBr}$, monobromobimane; NEM, $N$-ethylmaleimide.

J. Clin. Invest.

(C) The American Society for Clinical Investigation, Inc.

0021-9738/87/08/0557/09\$2.00

Volume 80, August 1987, 557-565 heterodimer self-associates (3) at one end (4) to form tetrameric (5) and oligomeric species $(6,7)$. Spectrin tetramers and oligomers are cross-linked by short filaments of F-actin (8-11). Protein $4.1^{2}$ greatly augments spectrin-actin binding (14-19).

Partial deficiency of spectrin has been observed in the red blood cells of both mutant mice (20-24) and humans $(25,26)$ with hereditary spherocytosis. There is a marked degree of deficiency in some patients with the clinically severe, apparently recessive form of $\mathrm{HS}$ (25). Recent studies by Agre and his colleagues $(26,27)$ show a correlation between the degree of spectrin deficiency and the unincubated osmotic fragility test, a measure of membrane loss (spheroidicity), as well as clinical severity and outcome after splenectomy for all patients with HS. In addition, a specific defect in spectrin function has been observed in three kindreds with HS. The protein 4.1 binding capacity of spectrin was found to be diminished $(28,29)$ because a fraction of spectrin was unable to bind protein 4.1 (29). This type of HS has been designated $\mathrm{HS}(S p-4.1)$ in a system of nomenclature proposed by Palek and Lux (30) and this molecular defect has only been observed in a small subset of patients with HS. This defect leads to a decrement in spectrin-actin binding in the presence of protein $4.1(28,29)$. Defective spectrin-actin binding may contribute to the increased membrane mechanical fragility observed (31) in the individuals from one of these kindreds (29). All other spectrin functions studied remained intact (29).

In this study, we sought evidence for abnormal structure of the spectrin isolated from the kindred with $\mathrm{HS}(S p-4.1)$ described by Wolfe and co-workers (29). Tryptic digestion with peptide analysis has been used to demonstrate the structural abnormalities of spectrin in hereditary elliptocytosis and hereditary pyropoikilocytosis (32-36), but this method has thus far failed to demonstrate abnormal structure of spectrin in most patients with HS. However, by studying the kinetics of enzymatic digestion, we were able to obtain evidence for aberrant structure of spectrin in HS in the region of the beta IV-T74 domain. ${ }^{3}$ This area coincides with the location of the presumed protein 4.1 binding site: the end of spectrin opposite to the oligomerization site $(38)$, probably the beta-chain $(39,40)$.

In addition, previous studies established that gentle chemical oxidation of normal spectrin reduced its protein 4.1 binding capacity (41), similar to the functional defect in $\operatorname{HS}(S p-4.1)$ spectrin. Chemical reduction fully reversed the functional defect

2. System of nomenclature for red cell membrane proteins by Fairbanks et al. (12), as modified by Steck (13).

3. Spectrin structure has been described as a linear sequence of enzymeresistance polypeptides (domains), with five on the alpha-chain and four on the beta-chain (37). Each domain can be designated by $(a)$ its chain of origin, $(b)$ its place in sequence in that chain by a Roman numeral, (c) the enzyme used for digestion ( $\mathrm{T}=$ trypsin, $\mathrm{C}=$ chymotrypsin), and (d) the molecular weight in $\mathrm{kD}$. 
in the oxidized spectrin (41). Similarly, we now find that chemical reduction of $\mathrm{HS}(S p-4.1)$ spectrin restores its protein 4.1 binding capacity to nearly normal levels. Hence, it is likely that the structural defect in the beta IV domain identified here exerts its effect on spectrin-protein 4.1 interactions through the mechanism of increased lability to oxidant damage.

\section{Methods}

Purification of spectrin dimer. Blood samples were obtained from a family with $\mathrm{HS}(S p-4.1)$, previously described (29). The affected individuals include the mother, age $33 \mathrm{yr}$, reticulocyte count $2.1 \%$, status postsplenectomy, and two daughters, aged 5 and $6 \mathrm{yr}$, with reticulocyte counts 15.7 and $5.6 \%$, respectively, both unsplenectomized at the time of this study. Hemoglobin-depleted membranes were prepared as described (12), in $5 \mathrm{mM}$ sodium phosphate, $0.5 \mathrm{mM}$ EGTA, pH 8. Diisopropylfluorophosphate (DFP; $1 \mathrm{mM}$ ) was used to inhibit proteolysis. The membranes were dialyzed against $0.1 \mathrm{mM}$ EDTA, $0.1 \mathrm{mM}$ sodium phosphate, $10 \mu \mathrm{g} / \mathrm{ml}$ phenylmethylsulfonylfluoride, $0.5 \mathrm{mM}$ sodium azide, $\mathrm{pH} 8$, for $12-16 \mathrm{~h}$ at $4^{\circ} \mathrm{C}$. They were then incubated at $37^{\circ} \mathrm{C}$ for $20 \mathrm{~min}$, followed by centrifugation at $100,000 \mathrm{~g}$ for $1 \mathrm{~h}$. The supernatant was chromatographed as described (42).

Preparation of F-actin. Actin was purified from rabbit muscle as described (43) with three cycles of polymerization-depolymerization. Factin $(2.5 \mathrm{mg} / \mathrm{ml})$ was prepared by addition of potassium and magnesium chloride to $50 \mathrm{mM}$ and $2 \mathrm{mM}$, respectively, in $2 \mathrm{mM}$ Tris, $0.2 \mathrm{mM}$ calcium chloride, $0.2 \mathrm{mM}$ ATP, $1 \mathrm{mM}$ dithiothreitol (DTT).

Purification of protein 4.1. Protein 4.1 was purified from human erythrocytes as described $(38,44)$.

Spectrin: protein 3 ratio determination. Freshly prepared hemoglobindepleted membranes were solubilized and run on a $3.5-17 \%$ exponential gradient sodium dodecyl sulfide (SDS)-polyacrylamide gel as described (12) and modified (25). The Coomassie Blue-stained bands of spectrin and protein 3 were cut from eight to ten lanes of membranes, the dye eluted with $25 \%$ pyridine, and the relative protein content estimated by spectrophotometry (45).

Limited tryptic digestions. Spectrin $(0.5-0.8 \mathrm{mg} / \mathrm{ml})$, in $10 \mathrm{mM}$ sodium phosphate, $40 \mathrm{mM} \mathrm{NaCl}, \mathrm{pH} 8$, was digested with trypsin- $N$-tosyl$L$-phenylalanine chloromethyl ketone (TPCK; Worthington Diagnostics, Freehold, NJ) with a ratio of trypsin to spectrin of 1:20 (wt/wt), for 90 min on ice (46). The digestion was terminated by the addition of $1 \mathrm{mM}$ DFP (for a two-dimensional gel) or by boiling for $5 \mathrm{~min}$ in gel sample buffer (for a one-dimensional gel). The one-dimensional gels were scanned with a soft laser densitometer (Zeineh, Biomed Instruments Inc., Fullerton, CA). Two-dimensional gel electrophoresis (for a domain map) was performed by the method of O'Farrell (47) as modified by Speicher et al. (37).

One-dimensional spectrin peptide maps with enzymes other than trypsin. Samples of spectrin dimer $(0.5-0.9 \mathrm{mg} / \mathrm{ml}$ in $10 \mathrm{mM}$ Tris, 150 $\mathrm{mM} \mathrm{NaCl}, 0.1 \mathrm{mM}$ EDTA [buffer A]) were digested with various enzymes for $2 \mathrm{~h}$ on ice at the following enzyme/substrate ratios (wt/wt): alphachymotrypsin (Worthington Diagnostics), 1:20; S. aureus V8 protease (Miles Laboratories Inc., Naperville, IL), 1:20; proteinase K (Boehringer Mannheim Biochemicals, Indianapolis, IN), 1:200; submaxillaris protease (Pierce Chemical Co., Rockford, IL), 1:20. The reaction was terminated by boiling in solubilizing solution. 50-100 $\mu \mathrm{g}$ of each digest was loaded on a $5 \% / 10 \%$ (stacking/separating) discontinuous SDS-polyacrylamide slab gel (48).

Separation of spectrin alpha- and beta-chains. The alpha- and betachains of spectrin were separated by a modification of the urea-DEAE chromatography method of Yoshino and Marchesi (49) using high-performance anion exchange liquid chromatography (HPLC). The initial elution buffer was $20 \mathrm{mM}$ Tris, $1 \mathrm{mM}$ EDTA, $3 \mathrm{M}$ urea, $\mathrm{pH} \mathrm{8}$, and the final elution buffer included $0.4 \mathrm{M} \mathrm{NaCl}$. The spectrin was fractionated using a HPLC system (Waters Associates, Milford, MA) and a Bio-Gel TSK DEAE-5PW $75 \times 7.5-\mathrm{mm}$ HPLC column (Bio-Rad Laboratories, Richmond, CA), equilibrated in $62 \%$ initial buffer $/ 38 \%$ final buffer kept at $4^{\circ} \mathrm{C}$. A 20 -min linear gradient was applied to $45 \%$ initial $/ 55 \%$ final buffer, maintained at this level for $20 \mathrm{~min}$, and then a gradient (curve 7 , slightly concave) was applied up to $100 \%$ final buffer. The fractions from the two peaks were examined on an SDS gel for purity, and fractions of $>90 \%$ purity were pooled and dialyzed against $20 \mathrm{mM}$ Tris, $\mathrm{pH} 8$, then concentrated by ultrafiltration to $0.1-0.5 \mathrm{mg} / \mathrm{ml}$.

Limited proteolytic digestion of the individual alpha- or beta-chains. The individual chains (concentration $0.15 \mathrm{mg} / \mathrm{ml}$ ), isolated from normal spectrin and spectrin from the individual with HS, were subjected to digestion by trypsin or chymotrypsin in a 1:20 ratio of enzyme to substrate $\left(\mathrm{wt} / \mathrm{wt}\right.$ ) for $45 \mathrm{~min}$ at $0^{\circ} \mathrm{C}$. The digestion was terminated by boiling. The peptides were examined by electrophoresis on a 5\%/12\% (stacking/separating) discontinuous SDS gel (48).

Thin-layer chromatography of chymotryptic digestions. The $88 \mathrm{~K}$ chymotryptic peptide (beta-C88) from normal beta spectrin and the betaIV-T74 peptide from normal spectrin were excised from SDS gels (onedimensional for the first two and two-dimensional for the third). The gel slices were then treated sequentially with methanol and isopropanol as described (50) and lyophilized. The peptides were radiolabeled with ${ }^{125}$ I (Amersham Corp., Arlington Heights, IL) and chloramine T (Pierce Chemical $\mathrm{Co}$.), then digested with alpha-chymotrypsin, and mapped on thin-layer cellulose plates (Eastman Kodak Co., Rochester, NY) using high voltage electrophoresis versus ascending chromatography, as described (37). The plates were then exposed to x-ray film (XAR-5; Eastman Kodak Co.) at $-60^{\circ} \mathrm{C}$ using fluorescence-intensifying screens.

Monoclonal antibody staining of chymotrypsin digestions. Spectrin low ionic strength extracts were prepared at $37^{\circ} \mathrm{C}$ as previously described (41). The protein concentration of each sample was adjusted to $0.8 \mathrm{mg} /$ $\mathrm{ml}$ and the buffer was adjusted to buffer $\mathrm{A}$ by additions from stock solutions. The extracts were then digested with alpha-chymotrypsin in a ratio of 1:17 (wt/wt) for various times $(0-6 \mathrm{~h})$ on ice. Digestion was terminated by treatment with $1 \mathrm{mM}$ DFP, followed by immediate freezing and lyophilization. The peptides were dissolved in SDS-gel sample buffer, and identical volumes of each sample were applied to the SDS-polyacrylamide gels, $5 \%$ stacking/ $12 \%$ separating (48). After gel electrophoresis, the proteins were electrophoretically transferred to nitrocellulose paper (51) for $4 \mathrm{~h}$ at $65 \mathrm{~V}$ in $25 \mathrm{mM}$ Tris, $192 \mathrm{mM}$ glycine, and $20 \%$ methanol. A monoclonal antibody designated IVC9 (52) directed against the COOH-terminal (proximal) portion of the human spectrin beta IV$74 \mathrm{~K}$ peptide, was used as the first antibody to stain the nitrocellulose blots together with a Vectastain Kit (Vector Laboratories, Inc., Burlington, CA) utilizing biotinylated anti-mouse IgG second antibody, avidin, biotinylated horseradish peroxidase, and chloronaphthol color reagent. The amount of immunoreactive peptide present was determined by densitometric scanning of the photographic negatives of the stained nitrocellulose transfers.

Spectrin-actin-protein 4.1 binding assay. Normal or HS spectrin (0$20 \mu \mathrm{g})$ was incubated with F-actin $(45 \mu \mathrm{g})$ in the absence or presence of protein $4.1(6 \mu \mathrm{g})$ for $90 \mathrm{~min}$ at $21^{\circ} \mathrm{C}$ in a total volume of $80 \mu \mathrm{l}$ as described (44), but omitting DTT. Alternatively, the same assay was performed with spectrin that had been treated with $25 \mathrm{mM}$ DTT for 1 $\mathrm{h}$ at $0^{\circ} \mathrm{C}$.

Analysis for disulfide bonds. To identify the spectrin peptides containing disulfide bonds, freshly isolated spectrin was first cleaved into domains with trypsin, then treated with $1 \mathrm{mM} N$-ethylmaleimide (NEM) (Pierce Chemical Co.) in $0.1 \mathrm{M}$ sodium phosphate, $\mathrm{pH} \mathrm{7}$, at $0^{\circ} \mathrm{C}$ for 1 $\mathrm{h}$ to block free sulfhydryl groups. From the time of spectrin extraction, all buffers were degassed under nitrogen to prevent in vitro oxidation, and the periods of time for dialysis at $4^{\circ} \mathrm{C}$ were limited to $6 \mathrm{~h}$. The NEMtreated peptides were dialyzed against buffer $\mathrm{A}$, then reduced with 20 mM DTT at $0^{\circ} \mathrm{C}$ for $1 \mathrm{~h}$, and dialyzed against $0.1 \mathrm{M}$ sodium phosphate, pH 7. Finally, they were modified with $3 \mathrm{mM}$ 5-(iodoacetamidoethyl)aminonaphthalene-1-sulfonic acid (IAEDANS) (Molecular Probes Inc., Junction City, OR) in $0.1 \mathrm{M}$ sodium phosphate, $\mathrm{pH} 7$, for $1 \mathrm{~h}$ on ice, then dialyzed against $50 \mathrm{mM}$ ammonium bicarbonate, $\mathrm{pH} 8$, frozen, and lyophilized. The peptides were analyzed using the two-dimensional domain map gel, described previously. The gel was photographed under shortwave UV light as soon as possible, to minimize photobleaching of the fluorescence. 


\section{Results}

There is also partial spectrin deficiency in $H S(S p-4.1)$, as in all other forms of $H S$. By quantitation of spectrin and protein 3 with dye elution, we determined a spectrin-to-protein 3 ratio of $1.01 \pm 0.01(\mathrm{SD})$ for the two normal individuals and $0.80 \pm 0.03$, $0.81 \pm 0.04$, and $0.84 \pm 0.05(S D)$ for the $\mathrm{HS}(S p-4.1)$ family members (mother, older daughter, younger daughter, respectively).

The alpha IV and alpha $V$ domains of $H S$ spectrin appear more rapidly than normal during tryptic digestion. The two-dimensional domain map of the HS(Sp-4.1) spectrin did not reveal qualitative changes in the peptide pattern (Fig. 1). However, there was a quantitative difference in the relative amount of two domains, the alpha IV-T52 and alpha V-T41, which was evident even after a standard 90-min limited digestion. These two polypeptides appeared more intense after Coomassie Blue staining than the same domains from a normal individual (Fig. 1), whereas all the other domains were of approximate equal intensity. Limited digestions with other enzymes (data not shown) did not reveal reproducible major differences. The abnormal tryptic sensitivity of $\mathrm{HS}(S p-4.1)$ spectrin was emphasized by a time course analysis employing one-dimensional peptide maps (data not shown). The alpha $\mathrm{V}$ domain appeared earlier, and both the alpha IV and alpha V domains were generated more rapidly (or degraded more slowly) (Fig. 2). The stain intensity for the alpha IV peptide was greater than that of the alpha $V$ because in a one-dimensional gel analysis, there is contribution to the staining in this region from the alpha III domain, which is also $52 \mathrm{kD}$. This domain appears early in the digest and persists at a relatively constant level (Fig. 1, triangle). The contribution of the alpha III is indicated in Fig. 2 by a dashed line, with the contribution of the alpha IV domain superimposed above it.

Only the beta-spectrin subunit is abnormal when isolated chains are enzymatically digested. To identify the site of putative structural change responsible for the differences in rate of tryptic digestion of intact dimeric spectrin, each of the isolated spectrin subunits was examined by tryptic and chymotryptic digestion. With trypsin, no differences were observed between normal and HS( $S p-4.1)$ spectrin alpha- or beta-subunits (Fig. $3 A$ ). Similarly, the peptides produced by limited chymotryptic digestion of the alpha-subunit from either normal or $\mathrm{HS}(S p-4.1)$ spectrin appeared identical (Fig. $3 \mathrm{~B}$ ). However, there was a striking difference between chymotryptic digestion patterns of the normal and HS beta-spectrin. A peptide of 74,000 D (beta-C74) was present in larger quantity in digests of the normal subunit, whereas a peptide of $88,000 \mathrm{D}$ (beta-C88) predominated in comparable digests of the HS spectrin beta-subunit (Fig. $3 \mathrm{~B}$ ). Again, this difference represents a quantitative distinction.

When these two peptides were analyzed by two-dimensional thin-layer cellulose peptide mapping, it was apparent that the beta-C74 from the normal spectrin was almost identical to the beta IV-T74 (Fig. 4, $A$ and $B$ ). Furthermore, the map of the beta-C88 peptide generated from the HS spectrin contained all the spots present in the beta-C74 map (Fig. 4, $B$ and $C$ ). In addition, the map of the beta-C88 contained three additional spots that were coincident with the map of the beta III-T33 (Fig. $4 \mathrm{D}$ ), indicating that the beta-C88 peptide not only contained the beta C-74, but also extended into the region of spectrin characterized as beta III-T33. Two additional spots on the beta IVC88 map not present in either the beta III or beta IV maps were found in a map of a beta-T104 peptide (data not shown). This peptide overlaps from the beta II through part of the beta IV domain. Presumably, the additional spots on the map of betaC88 present on the map of beta-T104 but not on the maps of beta-C74 or beta-T33 arose from the peptide joining the beta III and beta IV domains. Thus, the rate of normal cleavage at the beta III-IV junction which generates beta-C74 is impaired for the spectrin from patients with $\mathrm{HS}(S p-4.1)$.

Beta-subunit digestion by chymotrypsin of the HS(Sp-4.1) spectrin heterodimer is also impaired. In contrast to the chymotryptic digestion pattern of the isolated beta-subunit, the pattern of the intact spectrin dimer from the individual with HS appeared rather similar to that of the normal (Fig. $5 A$ ). This is likely to be due the presence of contaminating peptides in the 74-kD region, such as the alpha I-T74 (53). The use of the monoclonal antibody designated IVC9 (52) directed against the beta IV-T28 peptide near the $\mathrm{COOH}$-terminal end of the beta IV-T74 domain allowed this assumption to be examined. This antibody thus allowed the generation of the beta IV domain to be specifically followed by immunoblotting. These results are

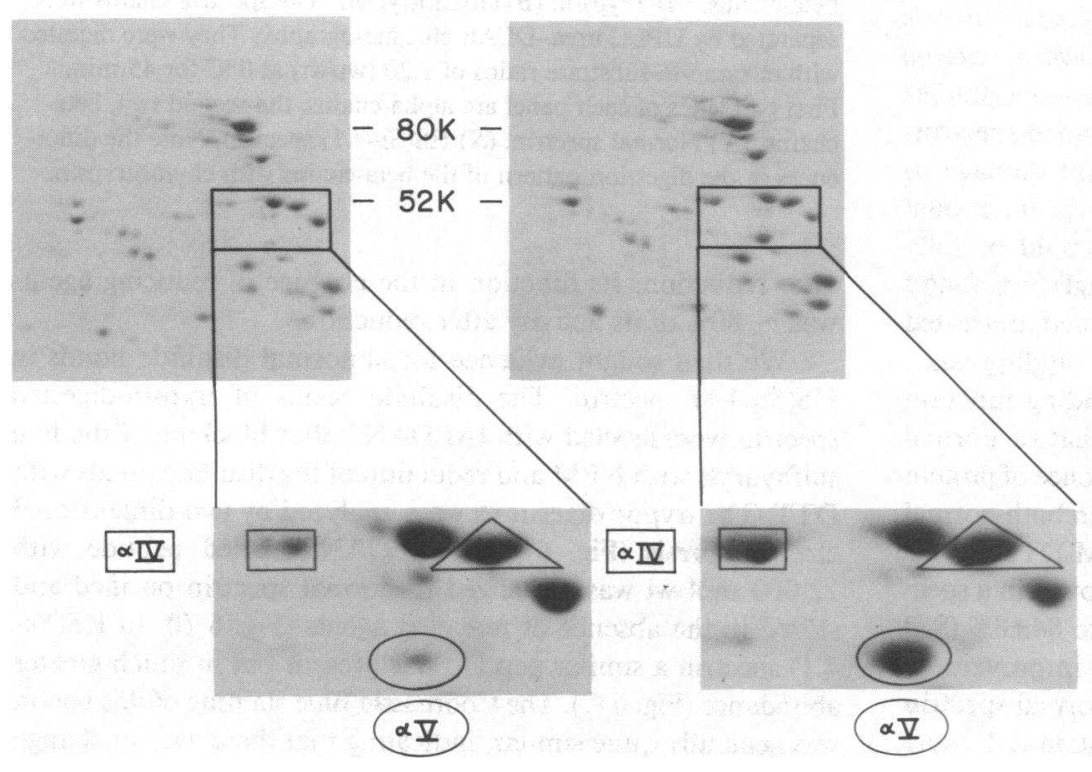

Figure 1. Two-dimensional domain maps of normal (left) and HS(Sp-4.1) (right) spectrin. Spectrin was digested for 90 min with trypsin 1:20, (wt/wt, enzyme-to-substrate) in $10 \mathrm{mM}$ sodium phosphate, $40 \mathrm{mM} \mathrm{NaCl}, \mathrm{pH} 8$, on ice. $200 \mu \mathrm{g}$ of peptides were applied to isoelectric focusing gels and then run on a discontinuous SDS-polyacrylamide 10$15 \%$ gradient gel (method of Speicher et al., 1982). The regions outlined by rectangles are magnified below. The alpha IV-T52 is enclosed by a rectangle in lower panels, and the alpha V-T41 is enclosed by an ellipse. Note the greater amounts of these two peptides present in the HS(Sp-4.1) (right) spectrin as compared with the normal control (left). The alpha III-T52 is enclosed by a triangle for comparison. 


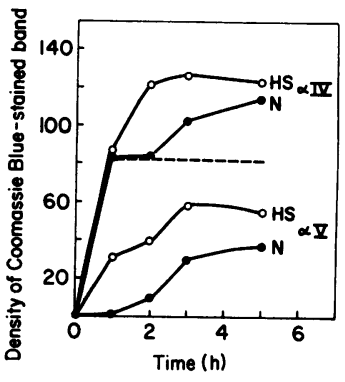

Figure 2. Kinetics of digestion of alpha IV and alpha $V$ domains in normal and $\mathrm{HS}(S p-4.1)$ spectrin. Upper two lines represent the intensity of the 52-kD peptide on a one-dimensional map and the differences represent the differences in the amounts of the alpha IV-T52. The only 52-kD peptide that appears different on a two-dimensional domain map is the alpha IVT52. The baseline (dashed line) is raised due to the high intensity of the alpha III-T52 peptide, of equal intensity in the normal and HS, as seen by the spots enclosed by triangles on Fig. 1. The lower two curves represent the intensity of the $41-\mathrm{kD}$ peptide on a one-dimensional map, corresponding to the alpha V-T41 on a two-dimensional map. (Open circles) HS(Sp-4.1); (closed circles) density of the Coomassie Blue-stained band (arbitrary units derived from the weights of the peaks cut from the paper tracing). Note that both the alpha IV and alpha $\mathrm{V}$ domains are in greater quantity at earlier times in the HS spectrin sample.

shown in Fig. $5 B$ and indicate that even for intact heterodimer, there was delayed generation of the beta IV domain. The blots show the late appearance of 70-, 65-, and 37-kD peptides in one of the three members of the family with HS, compared with a normal control (Fig. $5 \mathrm{~B}$ ). Similar results were obtained for the other two affected family members, whereas spectrin from an unaffected relative (father) was normal. The $70 / 65 \mathrm{kD}$ chymotryptic peptides appear to be the equivalent of the $74 / 70 \mathrm{kD}$ tryptic peptides $(52,54)$ of the beta IV domain recognized by the IVC9 monoclonal antibody. Note that the peptide pattern for the beta-chain is different for the digestion of the intact dimer as compared with the isolated beta-chain. Significantly, the generation of the beta IV domain only displayed biphasic kinetics for the individuals with HS (data not shown). 50\% of the 70/65 $\mathrm{kD}$ polypeptide was generated rapidly in these patients at a rate that paralleled the production of this domain in normal individuals. Peptides immunoreactive with beta IV appeared in the individuals with $\mathrm{HS}$ at 4-5 h, suggesting the presence of two classes of spectrin in the patients with HS: one with normal digestion kinetics and a second with a slower rate of generation of the beta IV domain.

Beta-chain structural abnormality exerts its effect on protein 4.1 binding via a destabilization of spectrin toward oxidant damage, a process which is reversed by DTT. Previous studies established that the ability of protein 4.1 to enhance spectrinactin binding was exquisitely sensitive to oxidant damage to spectrin (41). After oxidation of normal spectrin, the functional defect in protein 4.1-stimulated actin binding could be fully reversed by reduction with DTT (41). Surprisingly, we found that DTT also restored the function of freshly isolated, untreated $\mathrm{HS}(S p-4.1)$ spectrin in a spectrin-actin-protein 4.1 binding assay. Without DTT, the HS(Sp-4.1) spectrin-actin binding function in the absence of protein 4.1 was identical to that of normal spectrin, whereas it was reduced by $63 \%$ in the presence of protein 4.1 (data not shown; similar to reference 29). When both normal and $\mathrm{HS}(S p-4.1)$ spectrin were treated with $25 \mathrm{mM}$ DTT for $1 \mathrm{~h}$ at $0^{\circ} \mathrm{C}$, the function of $\mathrm{HS}(\mathrm{Sp}-4.1)$ spectrin improved in a spectrin-actin-protein 4.1 assay from $37 \pm 12 \%$ (SE) to $84 \pm 8 \%$ (SE) of the normal function (Table I). This functional improvement occurred in three independent binding assays. Normal spectrin also functioned better in the spectrin-actin-protein 4.1 assay
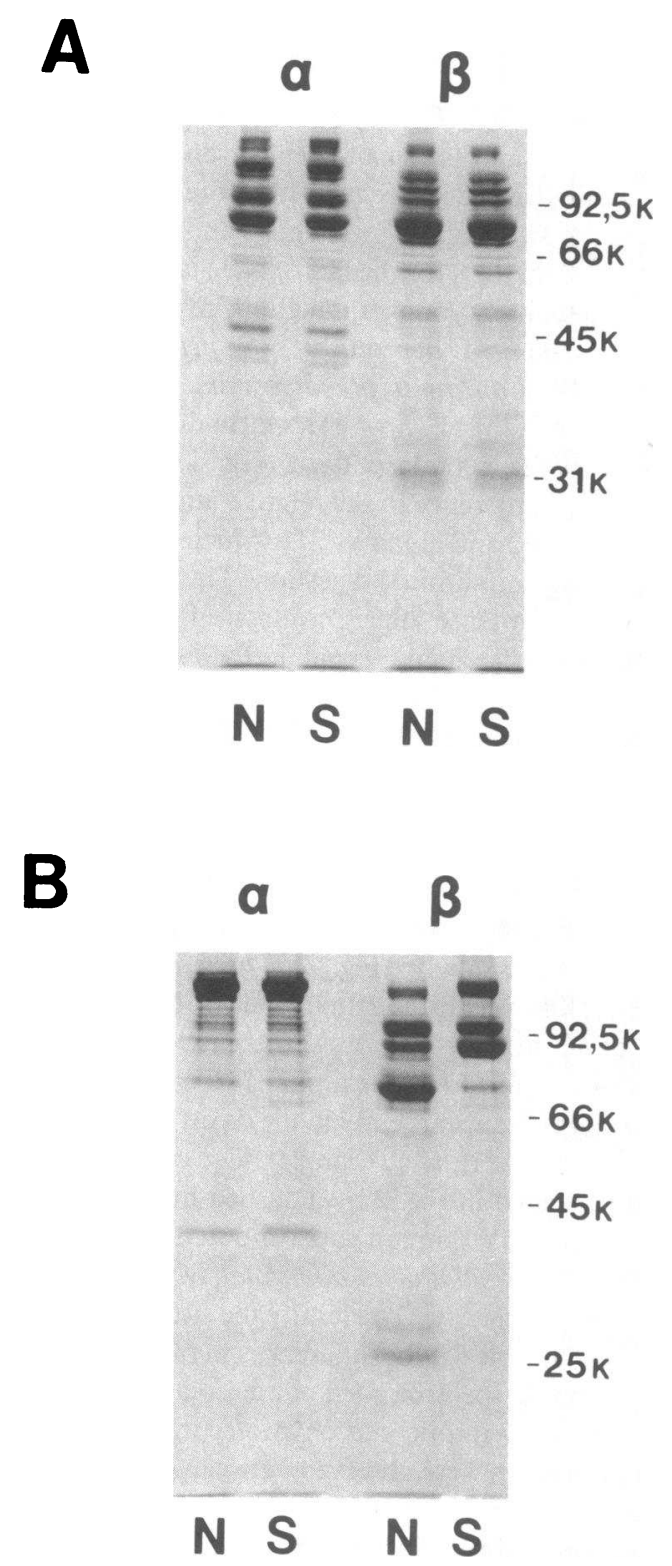

Figure 3. Tryptic and chymotryptic digestions of individual alpha- and beta-chains. $(A)$ Trypsin; $(B)$ chymotrypsin. The spectrin chains were separated by HPLC urea-DEAE chromatography. They were digested with enzyme-to-substrate ratios of $1: 20(\mathrm{wt} / \mathrm{wt})$ at $0^{\circ} \mathrm{C}$ for $45 \mathrm{~min}$. First two lanes of each panel are alpha-chains, the second two, betachains. ( $N$ ) Normal spectrin, $(S) \mathrm{HS}(S p-4.1)$ spectrin. Note the differences in the digestion pattern of the beta-chains with chymotrypsin.

after reduction. Its function in the absence of reducing agents was $\sim 80 \%$ of its activity after reduction.

We then sought evidence for abnormal disulfide bonds in $\mathrm{HS}(S p-4.1)$ spectrin. The disulfide bonds of trypsin-digested spectrin were labeled with IAEDANS after blocking of the free sulfhydryls with NEM and reduction of the disulfide bonds with DTT. The tryptic digestions were analyzed by two-dimensional electrophoresis (Fig. 6). An IAEDANS-labeled peptide with $22,000 \mathrm{~mol}$ wt was visualized in normal spectrin purified and stored in the absence of reducing agents (Fig. $6 \mathrm{~B}$ ). In HS( $S p$ 4.1) spectrin a similar peptide was present but in much greater abundance (Fig. $6 \mathrm{C}$ ). The Coomassie Blue staining of this region was generally quite similar, indicating that there was no change 


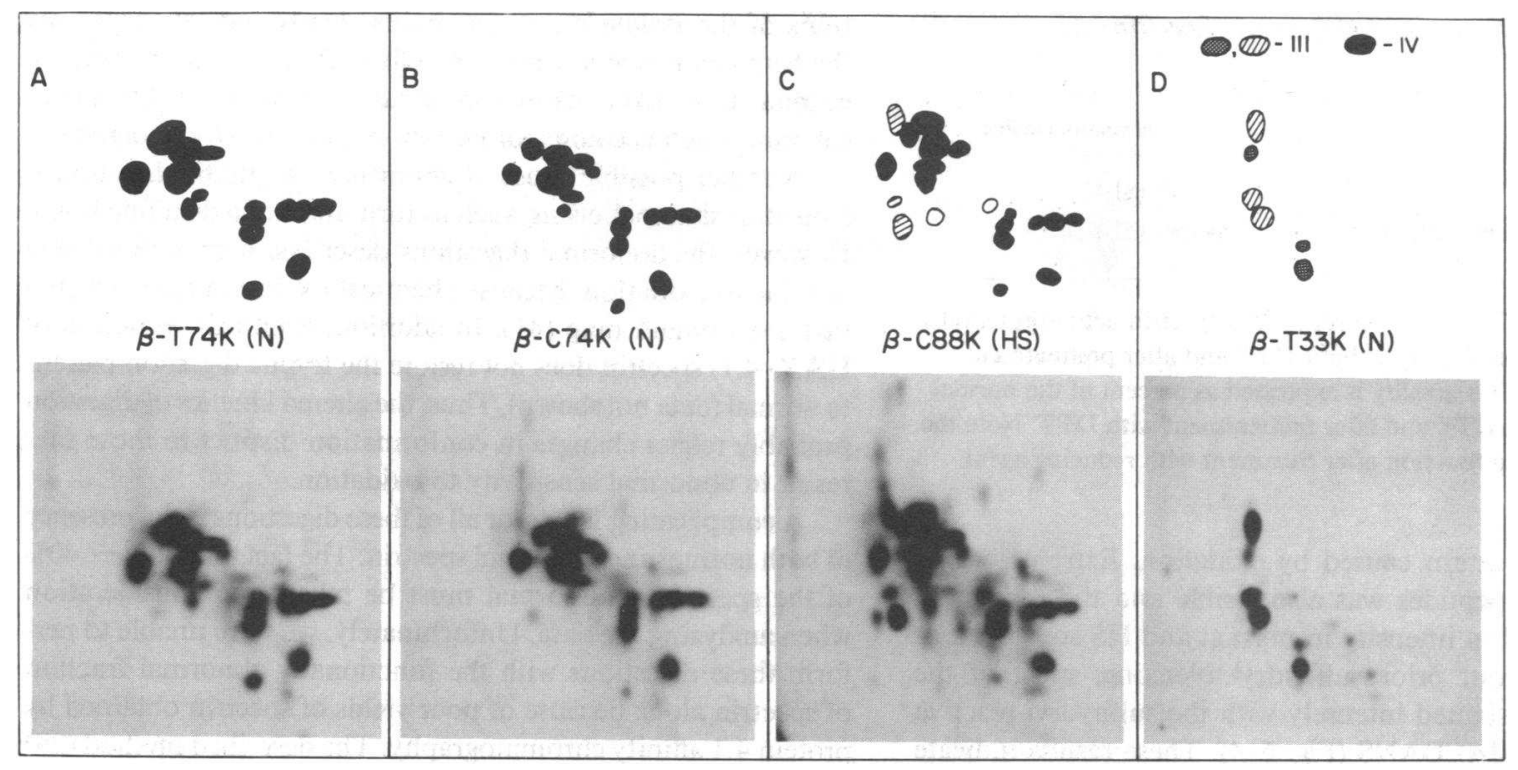

Figure 4. Cellulose peptide maps of normal beta-C74 and HS betaC88 peptides: comparison with normal tryptic peptides beta III-T33 and beta IV-T74. $(A)$ Normal beta IV-T74; $(B)$ normal beta-C74; $(C)$ HS beta-C88; $(D)$ normal beta III-T33. Upper panels are an artist's tracing and lower panels are photographs of the autoradiograms. The peptides mapped in $A$ and $B$ were excised from two-dimensional domain maps, whereas peptides mapped in $C$ and $D$ were excised from one-dimensional gels of the digested individual spectrin chains (Fig. 3 $B$ ). The peptide pattern from the beta IV-T74 tryptic polypeptide is preserved in the beta-C74 chymotryptic polypeptide (solid black spots). Beta-C88 polypeptide derived from HS spectrin also contains the basic pattern of the beta IV-T74 (solid spots), as well as additional spots that appear to derive from the beta III-T33 polypeptide (hatched spots). (Stippled spots) Beta III-T33 polypeptide not included in betaC88. (Open circles) Two additional prominent spots present on the beta-C88 not present on the beta III or beta IV maps. These two spots are present on a map of the beta-T104 (data not shown) that overlaps the beta II, III, and part of IV, and are not seen on any of the component maps, and therefore most likely represent parts of the joining region between beta III and IV. Thus, the HS beta-C 88 contains the beta IV-T74 and partially overlaps the beta III-T33.

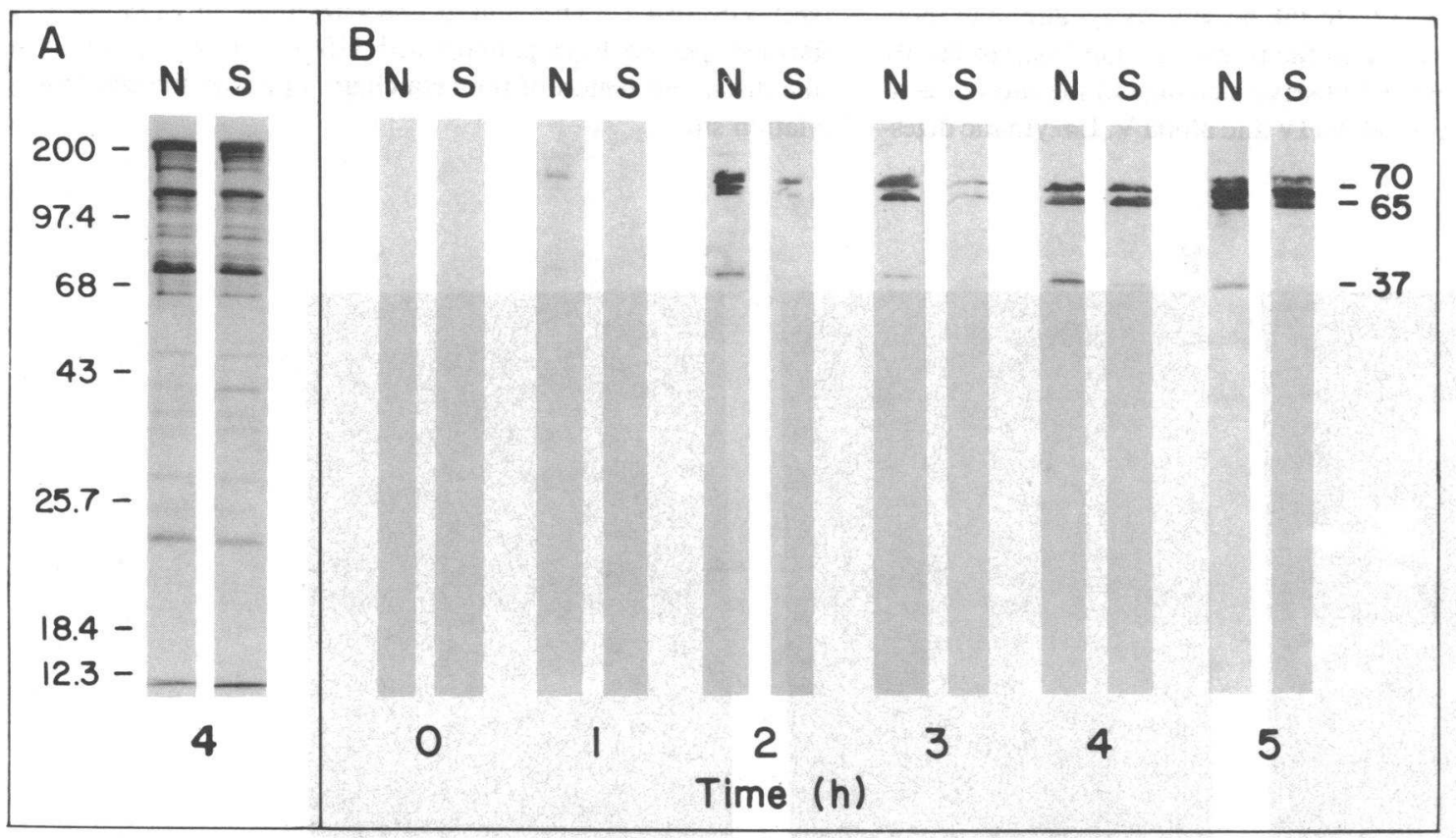

Figure 5. Monoclonal antibody staining of chymotryptic peptides from normal and HS spectrin. $(A)$ Shows a Coomassie Blue-stained gel of a 4-h $0^{\circ} \mathrm{C}$ chymotryptic digest of normal and HS spectrin. (B) Shows the chymotryptic digestions of normal and HS spectrin at various times of enzymatic digestion, after electrophoretic transfer to ni- trocellulose paper and staining by the monoclonal antibody IVC9 (51). Note the difference in intensity of the 70 - and $65-\mathrm{kD}$ polypeptides at early time points and the late appearance of the $37-\mathrm{kD}$ polypeptide in the HS spectrin. The same pattern was observed for all three affected family members with $\mathrm{HS}(S p-4.1)$. 
Table I. Improved Function of HS(Sp-4.1) Spectrin after Chemical Reduction

\begin{tabular}{ll}
\hline & Percent of control binding \\
\hline Without DTT & $37 \pm 12$ (SE) \\
After pretreatment with DTT & $84 \pm 8$ (SE)
\end{tabular}

The function of the HS(Sp-4.1) spectrin in a spectrin-actin-protein 4.1 binding assay was tested both without DTT and after pretreatment with $25 \mathrm{mM}$ DTT. This activity is expressed as percent of the normal control, also without DTT and after pretreatment with DTT. Note the restoration of binding function after treatment with reducing agent.

in the digestion pattern caused by oxidation. Extremely light labeling of other peptides was also visible and these peptides appeared identical in intensity in normal and HS spectrin. For comparison, without prior sulfhydryl blocking, most of the spectrin peptides stained intensely with the sulfhydryl-reactive fluorescent agent, IAEDANS (Fig. $6 A$ ). These results indicate that HS spectrin contains a significantly greater amount of oxidized sulfhydryl groups, all confined to a single region of the molecule.

\section{Discussion}

Several previous studies of spectrin from individuals with hereditary elliptocytosis and hereditary pyropoikilocytosis have correlated defective dimer-dimer association with changes in the digestion pattern of one of the domains responsible for that function, the alpha I-T80 (32-36, 55-58). In contrast, similar alterations in the spectrin domain map have not been reported in the autosomal dominant form of HS. There has been one report of an abnormal alpha-subunit in the recessively inherited type of spherocytosis (59). In the present study, although there was no qualitative change in the tryptic domain map in family members with HS, we did observe a change in the rates of generation of two domains, alpha IV and alpha V. Enzymatic diges- tions of the isolated spectrin chains clearly indicate that only the beta-chain is abnormal. Therefore, the defect of the beta IV domain most likely causes secondary alterations in the alphasubunit, which accounts for its abnormal sensitivity to digestion.

Another possible cause of abnormal enzymatic digestion is a posttranslational event, such as formation of a disulfide bond. However, the abnormal digestions described here are probably not due to oxidation, because chemical oxidation does not perturb the domain map (41). In addition, chemical reduction of $\mathrm{HS}(S p-4.1)$ spectrin does not restore the tryptic digestion pattern to normal (data not shown). Thus, the altered kinetics of digestion probably reflect changes in conformation distinct to those that result in abnormal sensitivity to oxidation.

A complicating factor for all of these digestions is the presence of both normal and abnormal spectrin. The fact that only $\sim 40 \%$ of the spectrin is abnormal must be taken into consideration when analyzing the data. Unfortunately, we were unable to perform these digestions with the functionally abnormal fraction of spectrin alone because of poor yields of spectrin obtained by protein 4.1 affinity chromatography. The described method (29) only results in isolation of microgram quantities of spectrin using milligram quantities of protein 4.1. We tried several methods of immobilizing protein 4.1 to obtain a method with a better yield, including cyanogen bromide-activated Sepharose 2B, CNBr-Sepharose 4B (Pharmacia Fine Chemicals, Piscataway, NJ), Affi-gel 10 (Bio-Rad Laboratories), in addition to Reactigel (Pierce Chemical Co.), but were not successful in improving the procedure. Without this internal control, we cannot absolutely assign our structural defect to the functionally defective spectrin. However, the altered digestion does persist in two members of a second generation within this family, arguing for linkage to the primary molecular abnormality.

Goodman and co-workers (60) also observed a difference in the digestion pattern of the beta-chain of spectrin from patients with $\mathrm{HS}(S p-4.1)$. They found that enzymatic digestion of ${ }^{32} \mathrm{P}$ labeled spectrin from patients with $\mathrm{HS}(S p-4.1)$ was different in the distal end region of the beta-chain, opposite the phosphorylation site.
A
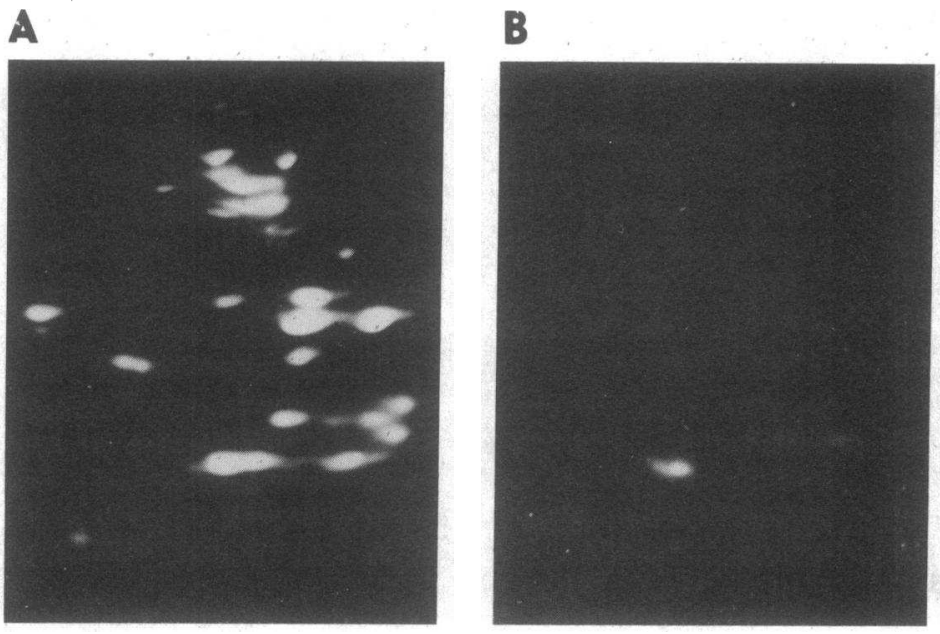

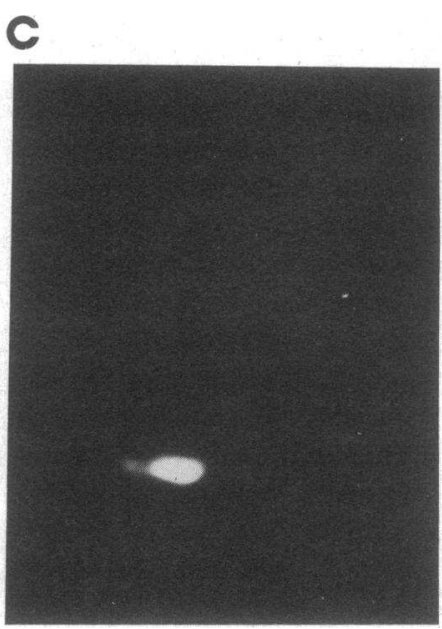

and $\mathrm{HS}(S p-4.1)$ spectrin, there appears to be a disulfide bond in a 22 $\mathrm{kD}$ peptide, with much greater fluorescence intensity in the $\mathrm{HS}$, suggesting that this peptide is more oxidized in the $H S(S p-4.1)$ spectrin. All other minor barely visible spots appear of equal intensity in normal and HS. 
In summary, the altered kinetics of digestion affecting the alpha IV and alpha V domains localizes the defect to the end of spectrin opposite the oligomerization site. Chymotrypsin digestion of the isolated spectrin chains supports a defect in the beta-chain, and the two-dimensional cellulose peptide mapping specifies the proximal region of the beta IV domain. Finally, the use of the monoclonal antibody directed against beta IV demonstrates that a similar defect exists in all family members affected by HS. This region of structural change correlates exactly with the location of the putative protein 4.1 binding site. Data supporting a binding site in the $\mathrm{NH}_{2}$-terminal region of the betachain are as follows: ( $a$ ) Previous electron microscopy by others demonstrated that protein 4.1 binds to the tail end of spectrin (38), opposite to the self-association site. (b) By using a radiolabel transfer cross-linking agent, we found that the beta-chain of spectrin appeared to carry the binding site for protein 4.1 (39). (c) The study of spectrin-actin binding with various spectrin isoforms demonstrated that the beta-subunit conferred protein 4.1 sensitivity on the spectrin-actin interaction (40).

Wolfe and co-workers (29) observed that $39 \%$ of the spectrin isolated from family members with $\mathrm{HS}$ was defective in its ability to bind to protein 4.1 , somewhat less than the predicted proportion of half if there were one abnormal spectrin gene in an autosomal dominant disorder. The spectrin content of $\mathrm{HS}(\mathrm{Sp}$ 4.1) red cells, $80 \%$ of normal, suggests the smaller fraction of abnormal spectrin is due to selective loss of the abnormal species. Another possible explanation is that the spectrin must be oxidized to be functionally defective, and that not all of the structurally defective spectrin is oxidized. Decreased spectrin could be the result of decreased synthesis, synthesis of an unstable spectrin, or impaired binding of spectrin to the membrane. We speculate that in this family, if the spectrin is unable to bind protein 4.1, it thereby loses one of its membrane attachment sites via protein 4.1 to glycophorin (61) and protein $3(62)$. This could cause it to become detached from the membrane and suffer enhanced degradation by intracellular proteases. Alternatively, if betaspectrin is rate limiting for spectrin assembly to the membrane (63) then loss of one membrane attachment site could result in spectrin deficiency. Or, weak spectrin-actin interactions could lead to membrane fragmentation and loss of spectrin in membrane vesicles. The erythrocyte membranes from this family with $\mathrm{HS}(S p-4.1)$ have been shown to have increased mechanical fragility $(31,64)$, and it is possible that membrane fragmentation occurs in vivo.

Modification of red blood cells with monofunctional (thiol) reagents or oxidants leads to a number of physiological changes in which the red cells appear similar to hereditary spherocytes. The red cells acquire the following characteristics: spheroidal shape, increased osmotic fragility, decreased deformability, decreased lifespan, and splenic sequestration (65-67). In previous studies, we found that mild chemical oxidation of spectrin markedly impaired its ability to bind protein 4.1 (41), similar to the defect observed for the HS(Sp-4.1) spectrin. In the absence of DTT, the function of the HS(Sp-4.1) spectrin is severely reduced (37\% of normal). Conversely, treatment of the HS(Sp4.1) spectrin with $25 \mathrm{mM}$ DTT restored function improved to $84 \%$ of normal. This functional improvement suggests that susceptibility to oxidant damage contributes to abnormal function.

We then sought to determine the location of the disulfide bond on a spectrin domain map after fluorescent labeling of thiols that had been in disulfide bonds. We did not find evidence for a disulfide bond in any of the characterized domains of
HS(Sp-4.1) spectrin. We found that a 22,000-D peptide was visible on a normal domain map under UV light but had much greater intensity on the domain map of $\mathrm{HS}(S p-4.1)$ spectrin. We do not know the origin of this peptide, because many domains have breakdown products in this molecular weight range (68), but speculate that it may originate from the alpha IV domain, which has a doublet breakdown product (69) in precisely the same location as the doublet $22-\mathrm{kD}$ peptide seen here. The alpha IV domain was also shown to be one domain (with beta IV) most sensitive to in vitro oxidation (41). We suspect that this $22-\mathrm{kD}$ peptide contains an oxidant-sensitive site in purified normal spectrin and is more sensitive in the case of the $\mathrm{HS}(S p-4.1)$ spectrin.

These studies suggest that the primary structural defect of spectrin in $\mathrm{HS}(S p-4.1)$ destabilizes the protein and predisposes it to oxidant injury in a neighboring region, which in turn leads to loss of protein 4.1-binding activity. Alternatively, primary amino acid sequence alteration may produce a conformational change that brings two SH groups in close proximity, possibly even by introducing a cysteine. If spectrin in $\mathrm{HS}(S p-4.1)$ were similarly oxidized in vivo, its function would be impaired and this functional defect could play a role in the pathophysiology of the hemolytic anemia. This role may provide an explanation for the variability of the clinical severity in HS, because variation in the redox state of the red cell, which would reflect the function of other metabolic processes, could affect spectrin function and thereby the membrane fragility.

\section{Acknowledgments}

We are grateful to Ms. Kathryn John and Dr. Lawrence Wolfe for helpful discussions, and to Ms. Linda Ardrey for providing excellent artwork and graphics. We thankfully acknowledge generous blood donations from the B. family toward this endeavor.

This investigation was supported by Public Health Service National Research Service Award 2T 32 GM07753-06 from the National Institute of General Medical Sciences (Dr. Becker), grants 5R01HL32262 and 5R01AM34083 (Dr. Lux), and 4R01HL28560 (Dr. Morrow) from the National Institutes of Health.

\section{References}

1. Becker, P. S., and S. E. Lux. 1985. Hereditary spherocytosis and related disorders. Clin. Haematol. 14:14-43.

2. Lange, Y., R. A. Hadesman, and T. L. Steck. 1982. Role of the reticulum in the stability and shape of the isolated human erythrocyte membrane. J. Cell Biol. 92:714-721.

3. Ungewickell, E., and W. Gratzer. 1978. Self-association of human spectrin. A thermodynamic and kinetic study. Eur. J. Biochem. 88:379385.

4. Morrow, J. S., D. W. Speicher, W. J. Knowles, J. Hsu, and V. T. Marchesi. 1980. Identification of functional domains of human erythrocyte spectrin. Proc. Natl. Acad. Sci. USA. 77:6592-6596.

5. Shotton, D. M., B. E. Burke, and D. Branton. 1979. The molecular structure of human erythrocyte spectrin. J. Mol. Biol. 131:303-309.

6. Morrow, J. S., and V. T. Marchesi. 1981. Self-assembly of spectrin oligomers in vitro: a basis for a dynamic skeleton. J. Cell Biol. 88:463468.

7. Liu, S. C., P. Windisch, S. Kim, and J. Palek. 1984. Oligomeric states of spectrin in normal erythrocyte membranes: biochemical and electron microscopic studies. Cell. 37:587-594.

8. Brenner, S. L., and E. D. Korn. 1979. Spectrin-actin interaction: phosphorylated and dephosphorylated spectrin tetramer cross-link Factin. J. Biol. Chem. 254:8620-8627. 
9. Cohen, C. M., J. M. Tyler, and D. Branton. 1980. Spectrin-actin associations studied by electron microscopy of shadowed preparations. Cell. 21:875-883.

10. Cohen, C. M., and S. F. Foley. 1980. Spectrin-dependent and -independent association of F-actin with the erythrocyte membrane. $J$. Cell Biol. 86:694-698.

11. Fowler, V. M., E. J. Luna, W. R. Hargreaves, D. L. Taylor, and D. Branton. 1981. Spectrin promotes the association of F-actin with the cytoplasmic surface of the human erythrocyte membrane. J. Cell Biol. 88:388-395.

12. Fairbanks, G., T. L. Steck, and D. F. H. Wallach. 1971. Electrophoretic analysis of the major polypeptides of the human erythrocyte membrane. Biochemistry. 10:2606-2617.

13. Steck, T. L. 1972. Cross-linking the major proteins of the isolated erythrocyte membrane. J. Mol. Biol. 66:295-305.

14. Ungewickell, E., P. M. Bennett, R. Calvert, V. Ohanian, and W. B. Gratzer. 1979. In vitro formation of a complex between cytoskeletal proteins of the human erythrocyte. Nature (Lond.). 280:811-814.

15. Cohen, C. M., and C. Korsgren. 1980. Band 4.1 causes spectrinactin gels to become thixotropic. Biochem. Biophys. Res. Commun. 97: 1429-1435.

16. Fowler, V., and D. L. Taylor. 1980. Spectrin plus band 4.1 crosslink actin. Regulation by micromolar calcium. J. Cell Biol. 85:361-376.

17. Cohen, C. M., and S. F. Foley. 1982. The role of band 4.1 in the association of actin with erythrocyte membranes. Biochim. Biophys. Acta. 688:691-701.

18. Ohanian, V., L. C. Wolfe, K. M. John, J. C. Pinder, S. E. Lux, and W. B. Gratzer. 1984. Analysis of the ternary interaction of the red cell membrane skeletal proteins spectrin, actin and 4.1. Biochemistry. 23:4416-4420.

19. Correas, I., T. L. Leto, D. W. Speicher, and V. T. Marchesi. 1984. Identification of the functional site of erythrocyte protein 4.1 involved in spectrin-actin associations. J. Biol. Chem. 261:3310-3315.

20. Greenquist, A. C., S. B. Shohet, and S. E. Bernstein. 1978. Marked reduction of spectrin in hereditary spherocytosis in the common house mouse. Blood. 51:1149-1155.

21. Lux, S. E. 1979. Spectrin-actin membrane skeleton of normal and abnormal red blood cells. Semin. Hematol. 16:21-51.

22. Shohet, S. B. 1979. Reconstitution of spectrin-deficient, spherocytic mouse erythrocyte membranes. J. Clin. Invest. 64:483-494.

23. Bernstein, S. E. 1980. Inherited hemolytic disease in mice: a review and update. Lab. Anim. Sci. 30:197-205.

24. Bodine, D. M., C. S. Birkenmeier, and J. E. Barker. 1984. Spectrin deficient inherited hemolytic anemias in the mouse: characterization by spectrin synthesis and mRNA activity in reticulocytes. Cell. 37:721-729.

25. Agre, P., E. P. Orringer, and V. Bennett. 1982. Deficient redcell spectrin in severe, recessively inherited spherocytosis. $N$. Engl. J. Med. 306:1155-1162.

26. Agre, P., J. F. Casella, W. H. Zinkham, C. McMillan, and V. Bennett. 1985. Partial deficiency of erythrocyte spectrin in hereditary spherocytosis. Nature (Lond.). 314:380-383.

27. Agre, P., A. Asimos, J. F. Casella, and C. Mcmillan. 1986. Inheritance pattern and clinical response to splenectomy as a reflection of erythrocyte spectrin deficiency in hereditary spherocytosis. $N$. Engl. $J$. Med. 315:1579-1583.

28. Goodman, S. R., K. A. Shiffer, L. A. Casoria, and M. E. Eyster. 1982. Identification of the molecular defect in the erythrocyte membrane skeleton of some kindreds with hereditary spherocytosis. Blood. 60:772784.

29. Wolfe, L. C., K. M. John, J. C. Falcone, A. M. Byrne, and S. E. Lux. 1982. A genetic defect in the binding of protein 4.1 to spectrin in a kindred with hereditary spherocytosis. N. Engl. J. Med. 307:13671374.

30. Palek, J., and S. E. Lux. 1983. Red cell membrane skeletal defects in hereditary and acquired hemolytic anemias. Semin. Hematol. 20:189_ 224.

31. Mohandas, N., M. R. Clark, B. P. Health, M. Rossi, L. C. Wolfe, S. E. Lux, and S. B. Shohet. 1982. A technique to detect reduced me- chanical stability of red cell membranes: revelance to elliptocytic disorders. Blood. 59:768-774.

32. Lawler, J., S. C. Liu, J. Palek, and J. Prchal. 1982. Molecular defect of spectrin in hereditary pyropoikilocytosis: alterations in the trypsin-resistant domain involved in spectrin self-association. J. Clin. Invest. 70:1019-1030.

33. Knowles, W. J., J. S. Morrow, D. W. Speicher, H. S. Zarkowsky, N. Mohandas, W. C. Mentzer, S. B. Shohet, and V. T. Marchesi. 1983. Molecular and functional changes in spectrin from patients with hereditary pyropoikilocytosis. J. Clin. Invest. 71:1867-1877.

34. Lawler, J., J. Palek, S. C. Liu, J. Prchal, and W. M. Butler. 1983. Molecular heterogeneity of hereditary pyropoikilocytosis: identification of a second variant of the spectrin alpha-subunit. Blood. 62:1182-1189.

35. Lawler, J., S. C. Liu, J. Palek, and J. Prchal. 1984. A molecular defect of spectrin in a subset of patients with hereditary elliptocytosis. Alterations in the alpha-subunit domain involved in spectrin self-association. J. Clin. Invest. 73:1688-1695.

36. Marchesi, S. L., W. J. Knowles, J. S. Morrow, M. Bologna, and V. T. Marchesi. 1986. Abnormal spectrin in hereditary elliptocytosis. Blood. 67:141-151.

37. Speicher, D. W., J. S. Morrow, W. J. Knowles, and V. T. Marchesi. 1982. A structural model of human erythrocyte spectrin: alignment of chemical and functional domains. J. Biol. Chem. 257:9093-9101.

38. Tyler, J. M., B. N. Reinhardt, and D. Branton. 1980. Association of erythrocyte membrane proteins: binding of purified bands 2.1 and 4.1 to spectrin. J. Biol. Chem. 255:7034-7039.

39. Becker, P. S., and S. E. Lux. 1984. Protein 4.1 binding peptides of human erythrocyte spectrin identified by use of a radiolabel transfer cross-linker. J. Cell Biol. 99:113a (Abstr.)

40. Coleman, T. R., A. S. Harris, S. M. Mische, M. S. Mooseker, and J. S. Morrow. 1987. Beta spectrin bestows protein 4.1 sensitivity on spectrin-actin interactions. J. Cell Biol. In press.

41. Becker, P. S., C. M. Cohen, and S. E. Lux. 1986. The effect of mild diamide oxidation on the structure and function of human erythrocyte spectrin. J. Biol. Chem. 261:4620-4628.

42. Harris, H. W., and S. E. Lux. 1980. Structural characterization of the phosphorylation sites of human erythrocyte spectrin. J. Biol. Chem. 255:11512-11520.

43. Spudich, J. A., and S. J. Watt. 1971. The regulation of rabbit skeletal muscle contraction. I. Biochemical studies of the interaction of the tropomyosin-troponin complex with actin and the proteolytic fragments of myosin. J. Biol. Chem. 246:4866-4871.

44. Becker, P. S., J. E. Spiegel, L. C. Wolfe, and S. E. Lux. 1983. High yield purification of protein 4.1 from human erythrocyte membranes. Anal. Biochem. 132:195-201.

45. Fenner, C., R. R. Traut, D. T. Mason, and J. Wikman-Coffelt. 1975. Quantification of Coomassie Blue-stained proteins in polyacrylamide gels based on analyses of eluted dye. Anal. Biochem. 63:595-602.

46. Speicher, D. W., J. S. Morrow, W. T. Knowles, and V. T. Marchesi. 1980. Identification of proteolytically resistant domains of human erythrocyte spectrin. Proc. Natl. Acad. Sci. USA. 77:5673-5677.

47. O'Farrell, P. H. 1975. High resolution two-dimensional electrophoresis of proteins. J. Biol. Chem. 250:4007-4021.

48. Laemmli, U. K. 1970. Cleavage of structural proteins during the assembly of the head of bacteriophage T4. Nature (Lond.). 227:680-685.

49. Yoshino, H., and V. T. Marchesi. 1984. Isolation of spectrin subunits and reassociation in vitro. Analysis by florescence polarization. J. Biol. Chem. 259:4496-4500.

50. Elder, J. H., R. A. Pickett, J. Hampton, and R. A. Lerner. 1977. Radioiodination of proteins in single polyacrylamide gel slices. J. Biol. Chem. 252:6510-6516.

51. Towbin, H., T. Staehelin, and J. Gordon. 1979. Electrophoretic transfer of proteins from polyacrylamide gels to nitrocellulose sheets: procedures and some applications. Proc. Natl. Acad. Sci. USA. 76:43504354

52. Harris, A. S., J. P. Anderson, P. D. Yurchenco, L. A. D. Green, K. J. Ainger, and J. S. Morrow. 1986. Mechanisms of cytoskeletal reg- 
ulation: functional and antigenic diversity in human erythrocyte and brain beta spectrin. J. Cell Biochem. 30:51-69.

53. Speicher, D. W., G. Davis, P. D. Yurchenco, and V. T. Marchesi. 1983. Structure of human erythrocyte spectrin. I. Isolation of the alphaI domain and its cyanogen bromide peptides. J. Biol. Chem. 258:1493114937.

54. Sears, D. E., V. T. Marchesi, and J. S. Morrow. 1986. A calmodulin and alpha-subunit binding domain in human erythrocyte spectrin. Biochim. Biophys. Acta. 870:432-442.

55. Lecomte, M. C., D. Dhermy, C. Solis, A. Ester, C. Feo, H. Gautero, $O$. Bournier, and P. Boivin. A new abnormal variant of spectrin in black patients with hereditary elliptocytosis. Blood. 65:1208-1217.

56. Lawler, J., T. L. Coetzer, J. Palek, H. S. Jacob, and N. L. C. Luban. 1985. Sp alpha I/65: a new variant of the alpha subunit of spectrin in hereditary elliptocytosis. Blood. 66:706-709.

57. Garbarz, M., M. C. Lecomte, D. Dhermy, C. Feo, I. Chaveroche, H. Gautero, O. Bournier, C. Picat, A. Goepp, and P. Boivin. 1986. Double inheritance of an alpha $\mathrm{I} / 65$ spectrin variant in a child with homozygous elliptocytosis. Blood. 67:1661-1667.

58. Alloisio, N., D. Guetarni, L. Morle, B. Pothier, M. T. Ducluzeau, A. Soun, P. Colonna, M. Clerc, N. Philippe, and J. Delaunay. 1986. Sp alpha I/65 hereditary elliptocytosis in North Africa. Am. J. Hematol. 23: 113-122.

59. Winkelmann, J. C., S. L. Marchesi, P. Watkins, A. J. Linnenbach, P. Agre, and B. G. Forget. 1986. Recessive hereditary spherocytosis is associated with an abnormal alpha spectrin subunit. Clin. Res. 34:474A. (Abstr.)

60. Goodman, S. R., J. J. Kesselring, S. A. Weidner, and E. M.
Eyster. 1981. The molecular alteration in the cytoskeleton of hereditary spherocytes. J. Supramol. Struct. Cell. Biochem. 1981:131. (Abstr.)

61. Anderson, R. A., and R. E. Lovrien. 1984. Glycophorin is linked by band 4.1 protein to the human erythrocyte membrane skeleton. Nature (Lond.). 307:655-658.

62. Pasternack, G. R., R. A. Anderson, T. L. Leto, and V. T. Marchesi. 1985. Interactions between protein 4.1 and band 3. J. Biol. Chem. 260: 3676-3683.

63. Moon, R. T., and E. Lazarides. 1983. Beta-spectrin limits alphaspectrin assembly on membranes following synthesis in a chicken erythroid cell lysate. Nature (Lond.). 305:62-65.

64. Waugh, R. E. 1983. Effects of abnormal cytoskeletal structure on erythrocyte membrane mechanical properties. Cell Motil. 3:609-622.

65. Jacob, H. S., and J. H. Jandl. 1962. Effects of sulfhydryl inhibition on red blood cells. I. Mechanism of hemolysis. J. Clin. Invest. 41:779792.

66. Jacob, H. S., and J. H. Jandl. 1962. Effects of sulfhydryl inhibition on red blood cells. II. Studies in vivo. J. Clin. Invest. 41:1514-1523.

67. Johnson, G. J., D. W. Allen, T. P. Flynn, B. Finkel, and J. G. White. 1980. Decreased survival in vivo of diamide-incubated dog erythrocytes. J. Clin. Invest. 66:955-961.

68. Speicher, D. W., and V. T. Marchesi. 1982. Spectrin domains: proteolytic susceptibility as a probe of protein structure. J. Cell. Biochem. 18:479-492.

69. Yurchenco, P. D., D. W. Speicher, J. S. Morrow, W. T. Knowles, and V. T. Marchesi. 1982. Monoclonal antibodies as probes of domain structure of the spectrin alpha subunit. J. Biol. Chem. 257:9102-9107. 